\title{
$\beta$-Cyclodextrin as a Metal-anionic Porphyrin Complexation Accelerator in Aqueous Media
}

\author{
Takao Ohtomo,* Aya Yokoyama, ** Mitsuyuki Konno,* Osamu Ohno, *** Shukuro Igarashi, ${ }^{* * *}$ \\ and Yoshitaka TAKAGAI $*, * * \dagger$
}

*Faculty of Symbiotic Systems Science, Fukushima University, 1 Kanayagawa, Fukushima 960-1296, Japan

**Institute of Environmental Radioactivity, Fukushima University, 1 Kanayagawa, Fukushima 960-1296, Japan

***Department of Biomolecular Functional Engineering, College of Engineering, Ibaraki University,

4-12-1, Nakanarusawa, Hitachi, Ibaraki 316-8511, Japan

\begin{abstract}
The rate of the complexation reaction between anionic porphyrins and 11 metal ions was found to be accelerated by the presence of $\beta$-cyclodextrin $(\beta$-CD) in aqueous media at room temperature without the need for additional heating or sonication. The porphyrin complexation reaction with metal ions under aqueous conditions can be difficult due to the strong hydration energy between the metal ions and water. In this study, the specific role of $\beta$-CD as an accelerator was determined and found to enhance the typically slow reaction of the porphyrin with metal ions. A significant acceleration effect was exhibited when the model anionic porphyrin, 5,10,15,20-tetraphenyl-21 $\mathrm{H}, 23 \mathrm{H}$-porphine-tetrasulfonic acid, and $\mathrm{Pb}$ (II) ions were combined in the presence of $\beta$ - $\mathrm{CD}$. Other than for $\mathrm{Hg}$ ion, the addition of $\beta$ - $\mathrm{CD}$ decreased the metalation reaction time from 30 to 2 min. The order in the degree of acceleration was $\mathrm{Pb}>\mathrm{Zn}, \mathrm{Cd}>\mathrm{Cu}>\mathrm{Fe}, \mathrm{Pd}>\mathrm{Sn}>\mathrm{Ag}$, $\mathrm{Co}, \mathrm{Mn}$. Using $\mathrm{Pb}$ (II) as the model ion, it was determined that the complexation rate constant was enhanced by a factor of 2.4, while the dissociation rate constant was diminished by a factor of 135 in the presence of added $\beta$-CD relative to that in its absence. Overall, the complex was much more stable (formation equilibrium constant 324-fold greater in the $\beta$-CD medium. The formation of a ternary complex (cf. bicapped complex; $(\beta \text {-CD })_{2}$-porphyrin-metal ion) was demonstrated through the use of nuclear magnetic-resonance spectroscopy and mass spectrometry. This acceleration effect is expected to be applicable systems in which porphyrin ligands are employed for determining of metal ions in chemical analysis and separation science.
\end{abstract}

Keywords $\beta$-Cyclodextrin, metal-anionic porphyrin complexation accelerator, TPPS $_{4}$

(Received October 14, 2015; Accepted February 1, 2016; Published June 10, 2016)

\section{Introduction}

Porphyrin derivatives are known to serve as very sensitive photometric or fluorophotometric reagents for the determination of metal ions. ${ }^{1-9}$ In addition, metal-porphyrin complexes have various functions that are useful in analytical chemistry, and are also of interest to many other researchers, which has led to the use of metal-porphyrin complexes in applications such as optics, ${ }^{10}$ chemical stacking, ${ }^{11}$ catalysis, ${ }^{12}$ electron transport, ${ }^{13}$ oxidation-reduction reactions, ${ }^{14}$ and biological mimicking substances. ${ }^{15,16}$ Thus, numerous reports regarding the chemical function and applications of porphyrin derivatives have been published.

Among the many useful porphyrin reagents, the anionic porphyrin 5,10,15,20-tetraphenyl-21 $H, 23 H$-porphine-tetrasulfonic acid $\left(\mathrm{TPPS}_{4}\right)$ has been widely utilized and has potential applications in many fields due to its unique properties, such as a very large molar absorptivity value $\left(\varepsilon_{413}=4.66,{ }^{17} 5.10,{ }^{18}\right.$ $5.30,{ }^{19}$ or $\left.5.24^{20} \times 10^{5} \mathrm{M}^{-1} \mathrm{~cm}^{-1}\right)$. However, complexation

$\dagger$ To whom correspondence should be addressed.

E-mail: s015@ipc.fukushima-u.ac.jp reactions between porphyrins, including $\mathrm{TPPS}_{4}$, and metals often require heating, ${ }^{21}$ sonication, ${ }^{22}$ the addition of special additives (catalysts), ${ }^{23}$ and/or a synthetic approaches (metal exchange reactions) ${ }^{24}$ to facilitate complexation, since the rate of metalloporphyrin formation is several orders of magnitude slower than that of complexation involving many other analytical ligands. Some metal ions can be inserted into the center of the $\mathrm{TPPS}_{4}$ porphine ring through heating, while heavy metal ions, including $\mathrm{Cd}, \mathrm{Pb}$, and $\mathrm{Hg}$, are known to form complexes with $\mathrm{TPPS}_{4}$ in a sitting-atop (SAT) structure ${ }^{25-29}$ due to their ionic radii. The sitting-atop structure of the $\mathrm{Pb}^{-T P P S}{ }_{4}$ complex is particularly useful in detecting $\mathrm{Pb}$ ions. ${ }^{30-34}$ Although many researchers are aware of the importance of $\mathrm{Pb}$ analysis and its applications, the requirement of a heating step has precluded the use of this method for heat-labile samples, especially biological samples and nanomaterials. ${ }^{21,23,24,35-37}$

Previously, Tabata ${ }^{23,26}$ reviewed five methods that can be employed to accelerate the rate of formation of metal-porphyrin complexes. These include: (1) the use of a substitution reaction for $\mathrm{Cd}(\mathrm{II})$ - or $\mathrm{Hg}(\mathrm{II})$-porphyrins, ${ }^{20,23,38,39}$ (2) the use of porphyrins with substituents at the pyrrole nitrogen, ${ }^{40,41}$ (3) the addition of aromatic, heterocyclic bases, ${ }^{42-44}$ (4) the introduction of functional groups to bind metal ions in the vicinity of the 
porphyrin nucleus, ${ }^{45}$ and (5) the use of an oxidation/reducing agent. ${ }^{46-48}$

In the present study, a new approach was developed in which $\beta$-cyclodextrin $(\beta$-CD) was employed to accelerate the complexation reaction between $\mathrm{TPPS}_{4}$ and 11 metal ions [( $\mathrm{Ag}(\mathrm{I})$, $\mathrm{Cd}(\mathrm{II}), \mathrm{Co}(\mathrm{II}), \mathrm{Cu}(\mathrm{II}), \mathrm{Fe}(\mathrm{II}), \mathrm{Fe}(\mathrm{III}), \mathrm{Mn}(\mathrm{II}), \mathrm{Pb}(\mathrm{II}), \mathrm{Pd}(\mathrm{II})$, $\mathrm{Sn}(\mathrm{II})$, and $\mathrm{Zn}(\mathrm{II})]$ in aqueous media at room temperature. Spectrophotometric kinetic measurements were made to follow the complexation reaction, while the nature of the $\mathrm{TPPS}_{4}-\mathrm{Pb}(\mathrm{II})$ $\beta$-CD complex was determined using nuclear magnetic resonance (NMR) spectroscopy and mass spectrometry (MS) measurements.

\section{Experimental}

\section{Reagents}

$\mathrm{TPPS}_{4}, \alpha$-cyclodextrin $(\alpha$-CD), $\beta$-CD, $\gamma$-cyclodextrin $(\gamma$-CD), heptakis(2,3,6-tri- $O$-methyl)- $\beta$-cyclodextrin (TMe- $\beta$-CD), and sodium tetraborate (borax) were obtained from Wako Pure Chemical Industries (Osaka, Japan). 5,10,15,20-Tetrakis(4carboxyphenyl)-21H,23H-porphine (TCPP) [5,10,15,20tetraphenyl-21H,23H-porphine-tetrasulfonic acid was obtained from Tokyo Chemical Industry (Tokyo, Japan). Standard stock solutions of 12 metal ions [Ag(I), Cd(II), Co(II), Cu(II), $\mathrm{Fe}(\mathrm{II})$, $\mathrm{Fe}(\mathrm{III}), \mathrm{Hg}(\mathrm{II}), \mathrm{Mn}(\mathrm{II}), \mathrm{Pb}(\mathrm{II}), \mathrm{Pd}(\mathrm{II}), \mathrm{Sn}(\mathrm{II})$, and $\mathrm{Zn}(\mathrm{II}))$ present at a concentration of $1000 \mathrm{ppm}$ were obtained from Nacalai Tesque, Inc. (Kyoto, Japan). All other reagents used were analytical grade.

\section{Measurements and experimental procedure}

A JASCO V-560 spectrophotometer (JASCO Inc., Tokyo, Japan) equipped with a JASCO EHC-477 single position Peltier thermostated cuvette holder was used along with a quartz cell having an optical path length of $1 \mathrm{~cm}$. A Hitachi F-7000 spectrofluorometer equipped with a thermostated cuvette holder (Hitachi High-Technology Co. Ltd., Tokyo, Japan) was employed. A JASCO SFS series rapid-scan photometer with a stopped-flow system was used. ${ }^{1} \mathrm{H}$ NMR spectra were acquired using a JEOL JNM-AL300 spectrometer (300 MHz). A Bruker AmaZon X Ion Trap Mass Spectrometer SL was used for complex identification.

Typically, $\mathrm{TPPS}_{4}(200 \mu \mathrm{L})$ and disodium tetraborate (Borax) $\mathrm{pH}$ buffer $(800 \mu \mathrm{L}, \mathrm{pH} 10.5,0.1 \mathrm{M})$ were mixed with $\beta$-CD in a spectrophotometer cuvette. The sample solution $(500 \mu \mathrm{L})$ including the metal ion was then added to the mixture in the cuvette with continuous stirring, the absorbance was immediately measured as a function of time.

\section{Results and Discussion}

Kinetic analysis of interaction of metal ions with TPPS 4

The 12 investigated metals [ $\mathrm{Ag}(\mathrm{I}), \mathrm{Cd}(\mathrm{II}), \mathrm{Co}(\mathrm{II}), \mathrm{Cu}(\mathrm{II})$, $\mathrm{Fe}(\mathrm{II}), \mathrm{Fe}(\mathrm{III}), \mathrm{Hg}$ (II), $\mathrm{Mn}$ (II), $\mathrm{Pb}$ (II), $\mathrm{Pd}(\mathrm{II}), \mathrm{Sn}(\mathrm{II})$, and $\mathrm{Zn}$ (II)] interact with $\mathrm{TPPS}_{4}$ to form metal-TPPS 4 complexes in which the metal ion is located in the center of the porphine ring. The times required for the formation of the metal-TPPS ${ }_{4}$ complexes in aqueous media (without any heating) in the absence and presences of added $\beta$-CD were determined. Acceleration was defined by the difference in rates between the complexation reaction in the presence of $\beta-\mathrm{CD}$ and its absence:

$$
\Delta(\mathrm{d} C / \mathrm{d} t)=\left[\left(\mathrm{d} C_{\text {without }} / \mathrm{d} t_{\text {without }}\right)-\left(\mathrm{d} C_{\text {with } \beta-\mathrm{CD}} / \mathrm{d} t_{\text {with } \beta-\mathrm{CD}}\right)\right],
$$

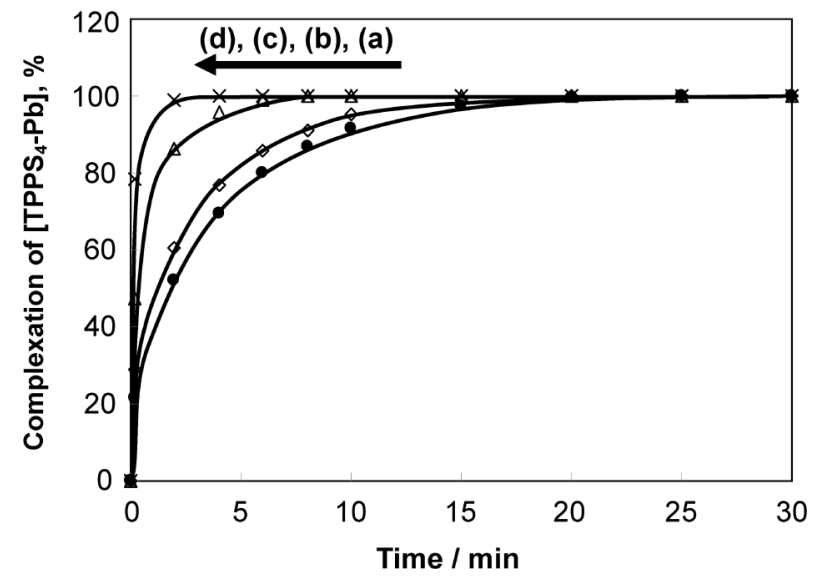

Fig. $1 \mathrm{~Pb}(\mathrm{II})-\mathrm{TPPS}_{4}$ complexation percent versus reaction time. $\left[\mathrm{TPPS}_{4}\right]_{\mathrm{T}}, 1.7 \mu \mathrm{M} ;\left[\mathrm{Pb}^{2+}\right]_{\mathrm{T}}, 10 \mu \mathrm{M} ; \mathrm{pH}, 10.5 ;[\beta-\mathrm{CD}]_{\mathrm{T}}$, (a) 0 , (b) 10 , (c) 50 , and (d) $1000 \mu \mathrm{M}$; temperature, $25^{\circ} \mathrm{C}$; and detection wavelength $\lambda_{\max }=$ (a) $464 \mathrm{~nm}$ and (b - d) $466 \mathrm{~nm}$.

where $C, C_{\text {without }}$, and $C_{\text {with } \beta \text {-CD }}$ are the metal-TPPS 4 complex concentrations, those in the absence of $\beta$-CD (without heat), and those in the presence of $\beta$-CD (without heat), respectively, and $t$ represents reaction time (s).

With the exception of $\mathrm{Hg}(\mathrm{II})$, the presence of $\beta$-CD decreased the complexation reaction time for all metal ions examined. The magnitude of the acceleration effect depended upon the specific metal ion, and followed the order: $\mathrm{Pb}>\mathrm{Zn}, \mathrm{Cd}>\mathrm{Cu}$ $>\mathrm{Fe}, \mathrm{Pd}>\mathrm{Sn}>\mathrm{Ag}, \mathrm{Co}, \mathrm{Mn}$. The trend in the acceleration effect roughly parallels the size (radius of the hydrated metal cation); i.e., the larger is the size, the greater is the acceleration effect (In the case of $\mathrm{Hg}(\mathrm{II})$, the addition of $\beta$-CD inhibited the complexation reaction (time required increased) relative to that in its absence). The metal ion, $\mathrm{Pb}(\mathrm{II})$, was used as the model ion to more fully examine this system and to demonstrate the complexation acceleration effect of $\beta$-CD addition, as $\mathrm{Pb}$ ion complexation is a subject of general interest to several fields of chemistry.

The reaction of $\mathrm{TPPS}_{4}$ and $\mathrm{Pb}(\mathrm{II})$ ions without $\beta$-CD required $30 \mathrm{~min}$ at room temperature. This complexation time was reduced to $2 \mathrm{~min}$ in the presence of $\beta-\mathrm{CD}$, as shown in Fig. 1, with the degree of acceleration depending on the concentration of $\beta$-CD (The profile of $\mathrm{Zn}$ (II) with $\mathrm{TPPS}_{4}$ is shown in Fig. S1 in Supporting Information). The greater the $\beta$-CD concentration, the faster is the metalation reaction. Consequently, $\beta$-CD was found to remarkably accelerate the formation of $\mathrm{Pb}$-TPPS complex. Based on these results, the pseudo-first-order reaction rates $\left(k_{0}\right)$ were obtained. In addition, it was preliminarily confirmed that $\mathrm{Pb}^{2+}$ did not react with $\beta$-CD. To obtain the complex formation $\left(k_{+}\right)$, dissociation $\left(k_{-}\right)$, and equilibrium $\left(K_{\mathrm{m}}\right)$ constants, the kinetic data were treated using the following equations:

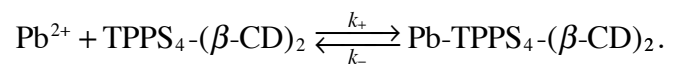

In this study, measuring the second order reaction rate with reactants $\left(\mathrm{TPPS}_{4}-(\beta-\mathrm{CD})\right.$ and $\left.\mathrm{Pb}^{2+}\right)$ could be experimentally problematic, because the concentrations of two reactants must be followed simultaneously. However, the forward reaction (complexation) can be regarded as pseudo-first order, when the concentration of TPPS $_{4}-(\mathrm{CD})_{2}$ is much higher than that of $\mathrm{Pb}^{2+}$ 


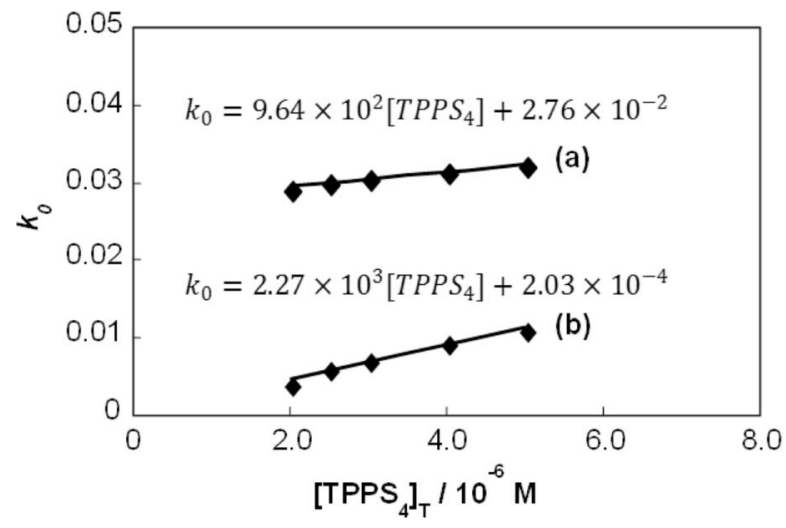

Fig. 2 Correlation equations between the pseudo-first-order rate constant $\left(k_{0}\right)$ and the concentration in (a) the absence and (b) presence of $\beta$-CD. [TPPS $]_{4}, 1.7$ to $4.2 \mu \mathrm{M} ;\left[\mathrm{Pb}^{2+}\right]_{\mathrm{T}}, 7.5 \times 10^{-7}$ to $7.5 \times 10^{-8} \mathrm{M}$ $[\beta-\mathrm{CD}]_{\mathrm{T}}, 1.0 \mathrm{mM}$; temperature, $25^{\circ} \mathrm{C}$; detection wavelength, $\lambda_{\max },=$ (a) 464 and (b) $466 \mathrm{~nm}$.

and the kinetic equation is followed as below;

$$
\begin{aligned}
\frac{d\left[\mathrm{~Pb}-\mathrm{TPPS}_{4}-(\mathrm{CD})_{2}\right]}{\mathrm{d} t} & \\
= & k_{+}\left(\left[\mathrm{Pb}^{2+}\right]_{0}-\left[\mathrm{Pb}-\mathrm{TPPS}_{4}-(\mathrm{CD})_{2}\right]\right)\left[\mathrm{TPPS}_{4}-(\mathrm{CD})_{2}\right]_{0} \\
& -k_{-}\left[\mathrm{Pb}-\mathrm{TPPS}_{4}-(\mathrm{CD})_{2}\right]
\end{aligned}
$$

The equation was given by integration, as below;

$$
\begin{aligned}
& \ln \left(\frac{1-\left(k_{+}\left[\mathrm{TPPS}_{4}\right]_{0}+k_{-}\right)\left[\mathrm{Pb}-\mathrm{TPPS}_{4}-(\mathrm{CD})_{2}\right]}{k_{+}[\mathrm{Pb}]_{0}}\right) \\
& \quad=-\left(k_{+}\left[\mathrm{TPPS}_{4}-(\mathrm{CD})_{2}\right]_{0}+k_{-}\right) t
\end{aligned}
$$

where $\left[\mathrm{TPPS}_{4}-(\beta-\mathrm{CD})_{2}\right]_{0}$ and $\left[\mathrm{Pb}^{2+}\right]_{0}$ were the initial concentrations of TPPS $4-(\beta-C D)_{2}$ and $\mathrm{Pb}^{2+}$, respectively. The $\left[\mathrm{Pb}-\mathrm{TPPS}_{4}-(\beta-\mathrm{CD})_{2}\right]$ is the concentration of Pb-TPPS $\mathrm{S}_{4}(\beta-\mathrm{CD})_{2}$ on the reaction time, $t$. The equation can be followed by Lambert-Beer's law, as follows;

$$
\ln \frac{A_{\mathrm{eq}}-A_{\mathrm{t}}}{A_{\mathrm{eq}}-A_{0}}=-\left(k_{+}\left[\mathrm{TPPS}_{4}-(\mathrm{CD})_{2}\right]_{0}+k_{-}\right) t=-k_{0} t
$$

where

$$
\begin{aligned}
& k_{0}=k_{+}\left[\mathrm{TPPS}_{4}-(\beta-\mathrm{CD})_{2}\right]_{0}+k_{-} \\
& K_{\mathrm{m}}=\frac{k_{+}}{k_{-}}
\end{aligned}
$$

Here, $A_{0}, A_{\mathrm{t}}$ and $A_{\text {eq }}$ denote the absorbance of the reaction time at reaction times $0, \mathrm{t}$, and the equilibrium state. A pseudo-first order plot can be obtained from plotting $\ln \left[\left(A_{\mathrm{eq}}-A_{\mathrm{t}}\right) /\left(A_{\mathrm{eq}}-A_{0}\right)\right]$ versus $t$. The observed rate constant $\left(k_{0}\right)$ was provided from the linear line. In addition, the values of $k_{0}$ were obtained in various lead concentrations. Based on these results, the dependence of the observed rate constants, $k_{0}$, upon the $\mathrm{TPPS}_{4}$ concentrations in (a) the absence and (b) the presence of $\beta$-CD is shown in Fig. 2. The rate constants for the forward reaction $\left(k_{+}\right)$and the reverse reaction $\left(k_{-}\right)$were obtained as the value of the slope and intercept of the liner line. The individual rate constants obtained for the metal ions $\mathrm{Pb}$ (II) and $\mathrm{Zn}$ (II) are summarized in Table 1.
Table 1 Additive effect of $\beta$-CD on the complexation of $\mathrm{Pb}(\mathrm{II})$ and $\mathrm{Zn}(\mathrm{II})-\mathrm{TPPS}_{4}$ : complex binding $\left(k_{+}\right)$, dissociation $\left(k_{-}\right)$, and equilibrium $\left(K_{\mathrm{m}}\right)$ constants

\begin{tabular}{clll}
\hline & \multicolumn{1}{c}{ Additive } & $k_{+} / \mathrm{M}^{-1} \mathrm{~s}^{-1}$ & $k / \mathrm{s}^{-1}$ \\
\hline $\mathrm{Pb}(\mathrm{II})$ & Without $\beta$-CD & $9.64 \times 10^{2}$ & $2.76 \times 10^{-2}$ \\
& With $\beta$-CD & $2.27 \times 10^{3}$ & $2.03 \times 10^{-4}$ \\
$\mathrm{Zn}$ (II) & Without $\beta$-CD & $0.68 \times 10^{2}$ & $2.75 \times 10^{-5}$ \\
& With $\beta$-CD & $1.25 \times 10^{2}$ & $1.21 \times 10^{-5}$ \\
\hline
\end{tabular}

Values obtained from correlation equations described in text.

The addition of $\beta$-CD enhanced the forward rate constant, $k_{+}$, for the complexation reaction between $\mathrm{TPPS}_{4}$ and $\mathrm{Pb}(\mathrm{II})$ by a factor of 2.4, while the reverse dissociation observed rate constant, $k_{-}$, was decreased by a factor of 135 compared to that in the absence of $\beta$-CD. Thus, the $\beta$-CD served to both suppress the dissociation reaction and to enhance the complexation reaction. These same general trends (both suppress the dissociation and enhance the complexation) held in the case for the complexation of $\mathrm{Zn}(\mathrm{II})$ with $\mathrm{TPPS}_{4}$. However, the magnitudes of the complexation acceleration effect and the dissociation rate diminution were much more modest (Table 1). Overall, the complexation equilibrium constant was only 1.8 -fold greater due to the addition of the $\beta$-CD. In contrast, the kinetic rate constants were reported with literature values as $2.16 \times 10^{2} \mathrm{M}^{-1} \mathrm{~s}^{-1}$ and $6.39 \times 10^{-11} \mathrm{M}^{-2} \mathrm{~s}^{-1}$ for $k_{+}$and $k_{-}$in the elementary reaction of TPPS and $\mathrm{Pb}$ ion (in the absence of CD). ${ }^{49}$ The equilibrium constants were also reported as being $10^{-0.43}$ and $10^{-9.97}$ for $\mathrm{Zn}$ and $\mathrm{Pb}$, respectively. ${ }^{50}$ In a comparison with this data, the value of $k_{+}$is very similar; otherwise, the value of $k_{-}$is quite different. This is included not only in the elementary reaction, but also concerning other reactions; therefore, the value of $k_{-}$represents the observed reserve rate constant.

\section{Spectroscopic behavior and impact of CD pore size}

The absorption spectra of $\mathrm{TPPS}_{4}$ and its $\mathrm{Pb}(\mathrm{II})$ complexes formed in the absence and presence of $\beta$-CD are shown in Fig. 3. The maximum absorption wavelength $\left(\lambda_{\max }\right)$ of $\mathrm{TPPS}_{4}$ (free-base type) was $413 \mathrm{~nm}$ (Fig. 3a), which shifted to $464 \mathrm{~nm}$ (Fig. 3b) upon complexation with $\mathrm{Pb}$ (II) after $30 \mathrm{~min}$. The $\lambda_{\max }$ of the complex was slightly shifted (to $466 \mathrm{~nm}$ ) in the presence of $\beta$-CD (Fig. 3c) with the molar absorptivity being increased slightly compared to the $\mathrm{Pb}_{-\mathrm{TPPS}_{4}}$ complex without $\beta$-CD $\left(\varepsilon_{464}=2.73 \times 10^{5} \mathrm{M}^{-1} \mathrm{~cm}^{-1}\right.$ for $\mathrm{Pb}_{-} \mathrm{TPPS}_{4}$ versus $\varepsilon_{466}=3.17 \times$ $10^{5} \mathrm{M}^{-1} \mathrm{~cm}^{-1}$ for Pb-TPPS $\left.4-(\beta-\mathrm{CD})_{2}\right)$.

The formation of bicapped complexes between $\mathrm{TPPS}_{4}$ and $\beta$-CD was previously reported in the literature. ${ }^{51,52}$ TPPS $_{4}$ contains four phenyl substituents, which are of appropriate size and shape to bind within the $\beta$-CD cavity, to form inclusion complexes. Among the possible $\beta$-CD-TPPS 4 stoichiometries, those with 2:1 CD:TPPS 4 stoichiometry in which two opposite phenyl moieties of the porphyrin ring are included into the $\mathrm{CD}$ cavity through its wider end have been reported to be the most stable. ${ }^{53}$ The addition of other CDs with various pore sizes (i.e., $\alpha$-CD, $\gamma$-CD, and TMe- $\beta$-CD) did not appreciably change the complexation rates of the tested metal ions relative to that in their absence. In the absence of $\mathrm{Pb}(\mathrm{II})$, inclusion complexes between CD and TPPS 4 were observed in the spectrophotometric profiles. The values of $\varepsilon$ were as follows: $\varepsilon_{416}=4.61 \times 10^{5}$ for TPPS $_{4}-(\mathrm{TMe}-\beta-\mathrm{CD})_{2}, \varepsilon_{413}=4.66 \times 10^{5}$ for $\mathrm{TPPS}_{4}, \varepsilon_{413}=4.70 \times$ $10^{5}$ for $\operatorname{TPPS}_{4}-(\alpha-\mathrm{CD})_{2}, \varepsilon_{415}=4.79 \times 10^{5}$ for $\mathrm{TPPS}_{4}-(\gamma-\mathrm{CD})_{2}$, and $\varepsilon_{416}=4.85 \times 10^{5} \mathrm{M}^{-1} \mathrm{~cm}^{-1}$ for $\mathrm{TPPS}_{4}-(\beta-\mathrm{CD})_{2}$ (absorbance 


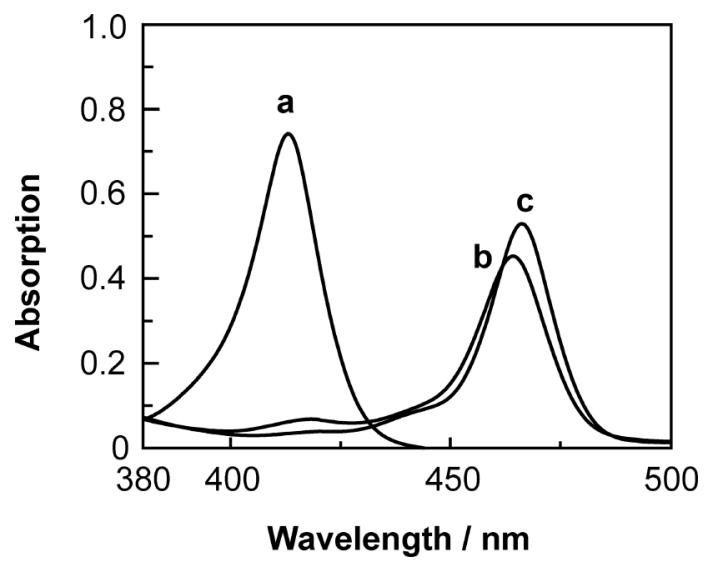

Fig. 3 Absorption spectra of (a) $\mathrm{TPPS}_{4}$, (b) $\mathrm{Pb}_{-\mathrm{TPPS}_{4}}$ complex, and (c) $\mathrm{Pb}-\mathrm{TPPS}_{4}$ complex with $\beta$-CD. Spectrum a: $\left[\mathrm{TPPS}_{4}\right]_{\mathrm{T}}, 1.7 \mu \mathrm{M} ; \mathrm{pH}$, 10.5; and temperature, $25^{\circ} \mathrm{C}$. Spectrum b: $\left[\mathrm{TPPS}_{4}\right]_{\mathrm{T}}, 1.7 \mu \mathrm{M} ;\left[\mathrm{Pb}^{2+}\right]_{\mathrm{T}}$, $10 \mu \mathrm{M} ; \mathrm{pH}, 10.5$; temperature, $25^{\circ} \mathrm{C}$; and reaction time, $30 \mathrm{~min}$. Spectrum c: $\left[\mathrm{TPPS}_{4}\right]_{\mathrm{T}}, 1.7 \mu \mathrm{M} ;\left[\mathrm{Pb}^{2+}\right]_{\mathrm{T}}, 10 \mu \mathrm{M} ;[\beta-\mathrm{CD}]_{\mathrm{T}}, 10 \mathrm{mM} ; \mathrm{pH}$, 10.5; temperature, $25^{\circ} \mathrm{C}$, and reaction time, $4 \mathrm{~min}$. The maximum wavelengths $\left(\lambda_{\max }\right)$ of spectra $\mathrm{a}-\mathrm{c}$ are 413,464 , and $466 \mathrm{~nm}$, respectively.

spectra are shown in Fig. S2 in Supporting Information). Furthermore, fluorescence sensitization arose from the formation of $\mathrm{TPPS}_{4}-(\mathrm{CD})_{2}$ bicapped complexes with the sensitization increasing in the following order: $\mathrm{TPPS}_{4}<\mathrm{TPPS}_{4}-(\alpha-\mathrm{CD})_{2}<$ TPPS $_{4}-(\gamma-\mathrm{CD})_{2}<\mathrm{TPPS}_{4}-(\beta-\mathrm{CD})_{2}<\mathrm{TPPS}_{4}-(\mathrm{TMe}-\beta-\mathrm{CD})_{2}$ (emission spectra shown in Fig. S3 in Supporting Information). The TPPS $_{4}$-(TMe- $\beta$-CD) $)_{2}$ complex exhibited the highest binding constant $\left(2.92 \times 10^{13} \mathrm{~mol}^{-2} \mathrm{dm}\right)^{54,55}$ among the $\mathrm{TPPS}_{4}-(\mathrm{CD})_{2}$ complexes. $^{51,52}$ Thus, it is considered that the use of larger CD and/or strong binding to the porphyrin rings $\left(\right.$ e.g., TPPS $\left._{4}-(\gamma-\mathrm{CD})_{2}\right)$ inhibits the insertion of metal ions into the porphyrin ring due to steric hindrance. In contrast, the cavity size of $\alpha$-CD was insufficient to bind or cap TPPS 4 , and thus had little impact the kinetics of metal ion binding. Thus, $\beta$-CD appears to be optimal in terms of enhancing the rate for $\mathrm{TPPS}_{4}$-metal ion complexation reactions.

${ }^{1} \mathrm{H} N M R$ studies of the reaction between the $\mathrm{TPPS}_{4}-(\beta-C D)_{2}$ complex and $\mathrm{Pb}$ ion

The interaction between $\mathrm{Pb}(\mathrm{II})$ ions and $\mathrm{TPPS}_{4}-(\beta-\mathrm{CD})_{2}$ was investigated by ${ }^{1} \mathrm{H}$ NMR spectroscopy. Typically, $\mathrm{TPPS}_{4}$ has three ${ }^{1} \mathrm{H}$ NMR signals corresponding to $\mathrm{H}^{\circ}$ and $\mathrm{H}^{\mathrm{m}}$ (singlet at $\delta 8.8$ and doublets at $\delta 8.2$ and $\delta 7.65 \mathrm{ppm}$ ), as shown in Fig. S4 in Supporting Information. During the formation of TPPS 4 - $(\beta$ $\mathrm{CD})_{2}$, the $\mathrm{H}^{\circ}$ doublet at $\delta 7.65 \mathrm{ppm}$ disappeared by $\mathrm{CD}$ capping to $\mathrm{TPPS}_{4}$. Under the molar ratio conditions of TPPS 4 : $\beta-\mathrm{CD}=$ $1: 2$, while the $\mathrm{H}^{\mathrm{m}}$ doublet remained at any $\beta$-CD concentration, ${ }^{56,57}$ the $\mathrm{H}_{\mathrm{i}}{ }^{\mathrm{o}}, \mathrm{H}_{\mathrm{i}}^{\mathrm{\beta}}{ }^{\mathrm{p} p \mathrm{y}}$, and $\mathrm{H}^{\beta-p y}$ singlets (in TPPS ${ }_{4}$ ) appeared along with an increase of $\beta$-CD. In particular, it was found that the pyrrole of the porphyrin ring and the phenyl group of porphine were influenced by CD inclusion (capping); therefore, the $\mathrm{p} K_{\mathrm{a}}$ values of the porphyrin ring would most likely change. In contrast, the formation of the Pb-TPPS ${ }_{4}$ complex (in the absence of $\beta$-CD) demonstrated a lack of the three ${ }^{1} \mathrm{H}$ NMR signals corresponding to $\mathrm{H}^{\circ}$ and $\mathrm{H}^{\mathrm{m}}$ in $\mathrm{TPPS}_{4}$ at a molar ratio of $\mathrm{Pb}_{\mathrm{TPPS}}=1: 1$ (Fig. S5 in Supporting Information). In addition, the singles disappeared in the presence of excess $\mathrm{Pb}^{2+}$ concentration. This is considered to mean that the $\mathrm{TPPS}_{4}$ decreases in the ionic activity with an excess concentration of $\mathrm{Pb}^{2+}$, and thus the
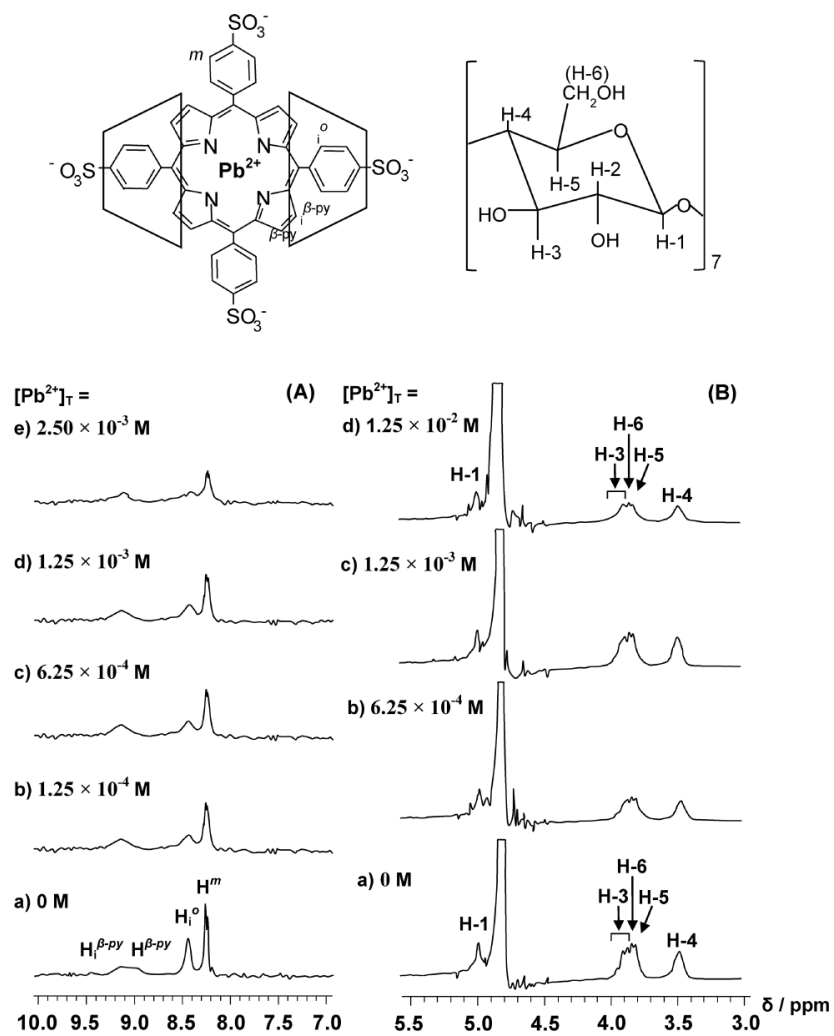

Fig. 4 Transition of ${ }^{1} \mathrm{H} N M R$ spectra during $\mathrm{TPPS}_{4}-(\beta-\mathrm{CD})_{2}$ complexation with $\mathrm{Pb}$ in $\mathrm{D}_{2} \mathrm{O}$. [TPPS $]_{\mathrm{T}}, 1.25 \mathrm{mM} ;[\beta-\mathrm{CD}]_{\mathrm{T}}, 2.50 \mathrm{mM}$ borax buffer at $\mathrm{pH} 10.5$, and $25^{\circ} \mathrm{C}$. "i" represents the protons inside the CD cavity. Chemical shift corresponding to (A) $\mathrm{TPPS}_{4}$ and (B) $\beta$-CD.

H NMR signals are influenced.

On the other hand, the interaction between $\beta$ - $\mathrm{CD}$ and $\mathrm{Pb}(\mathrm{II})$ ion was not observed in the ${ }^{1} \mathrm{H}$ NMR spectra of $\beta$-CD (Fig. S6 in Supporting Information). Upon the formation of $\mathrm{TPPS}_{4}-(\beta$ $\mathrm{CD})_{2}$, as shown in Fig. S7 in Supporting Information, the original ${ }^{1} \mathrm{H}$ NMR spectra of $\beta$-CD changed to the five signals in $\beta$-CD corresponding to $\mathrm{H}-1, \mathrm{H}-3, \mathrm{H}-6, \mathrm{H}-5$ and $\mathrm{H}-4$. Based on these NMR profiles, the reaction between TPPS $_{4}-(\beta-\mathrm{CD})_{2}$ and $\mathrm{Pb}$ (II) ions was eventually tracked, as shown in Fig. 4. In the TPPS $_{4}$ region $(10-7 \mathrm{ppm})$ of the ${ }^{1} \mathrm{H}$ NMR spectrum of $\mathrm{TPPS}_{4-}$ $(\beta \text {-CD })_{2}$, a doublet $(\delta 8.2 \mathrm{ppm})$ for $\mathrm{H}^{\mathrm{m}}$ in $\mathrm{TPPS}_{4}$ remained, while the other signals disappeared with increasing $\mathrm{Pb}$ (II) concentration (Fig. 4(A)). Conversely, in the $\beta$-CD region $(5.5-3 \mathrm{ppm})$ of TPPS $_{4}-(\beta-\mathrm{CD})_{2}$, one doublet for H-3 in $\beta$-CD was converted to a singlet (Fig. 4(B)). Thus, it was found that TPPS $_{4}-(\beta-C D)_{2}$ and metal ions form a bicapped ternary complex of metalTPPS $_{4}-(\beta-\mathrm{CD})_{2}$. As a result of NMR tracking, obvious differences in the chemical shifts in the presence and absence of $\beta$-CD were confirmed. This is considered to involve the formation of a ternary complex (cf. bicapped complex; $(\beta-\mathrm{CD})_{2}-$ porphyrin-metal ion). As a complementary fact, the $1: 1$ complexation between $\mathrm{TPPS}_{4}-(\beta-\mathrm{CD})_{2}$ and $\mathrm{Pb}^{2+}$ was spectrophotometrically confirmed by the mole ratio method, as shown in Fig. S8, as Supporting Information. In addition, the $\mathrm{Pb}^{-} \mathrm{TPPS}_{4}-(\beta-\mathrm{CD})_{2}$ ternary complex was supported by the mass spectrum, as shown in Fig. S9 in Supporting Information.

\section{Impact of $p H$ on the acceleration effect}

The optimum $\mathrm{pH}$ for both reactions (with and without $\beta$-CD) was 10.5. However, the range of the $\mathrm{pH}$ in which the reaction 


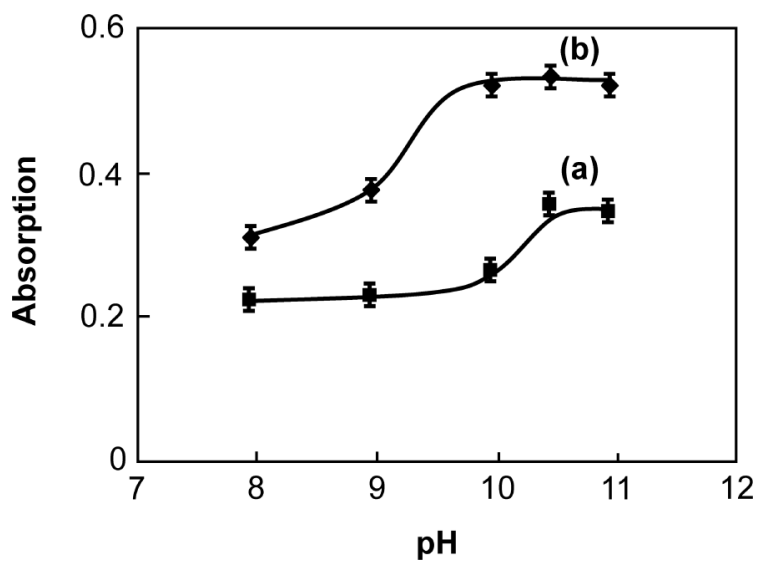

Fig. 5 Absorbance-pH curves in (a) the absence and (b) presence of $\beta$-CD. $\left[\mathrm{TPPS}_{4}\right]_{\mathrm{T}}, 1.7 \mu \mathrm{M} ;\left[\mathrm{Pb}^{2+}\right]_{\mathrm{T}}, 10 \mu \mathrm{M} ;[\beta-\mathrm{CD}]_{\mathrm{T}}$, (a) 0 and (b) $1.0 \mathrm{mM}$; temperature, $25^{\circ} \mathrm{C}$; and reaction time, $4 \mathrm{~min}$.

occurred was expanded to 9.5 - 11 upon the addition of $\beta$-CD, as shown in Fig. 5. Thus, it is assumed that the $\mathrm{p} K_{\mathrm{a}}$ values decreased slightly (position of $\mathrm{N}-\mathrm{H}$ in the porphine ring), thus allowing for easier complexation of the metal ions with the porphyrin (in the presence of $\beta$-CD). Likewise, the $\mathrm{p} K_{\mathrm{a}}$ variation, which is caused by a structural variation, was reported to slow that asymmetric porphyrins possess lower $\mathrm{p} K_{\mathrm{a}}$ values than symmetric porphyrins. ${ }^{38,40}$ In addition, it was previously noted in the literature that deprotonation slightly opens (distorts) the porphyrin ring, which facilitates complexation with the incoming metal ion ${ }^{58}$ and also that the addition of $\beta$-CD likely enhances this effect. This is supported by the results of the NMR profile corresponding to $\mathrm{H}_{\mathrm{i}}{ }^{\beta-p y}$ and $\mathrm{H}^{\beta-p y}$ signal transitions (in the pyrrole ring) in Fig. S4 in Supporting Information.

\section{Utilization of another anionic porphyrin}

A brief study was conducted using another anionic porphyrin TCPP, which has four carboxyl groups. It was found that only the addition of $\beta$-CD accelerated the complexation reaction between TCPP and $\mathrm{Pb}(\mathrm{II})$ ions, as shown in Fig. 6. A similar trend with TPPS $_{4}$ was observed. The maximum absorption wavelength $\left(\lambda_{\max }\right)$ of TCPP was $413 \mathrm{~nm}$ (Fig. 6a), which shifted immediately to $416 \mathrm{~nm}$ (Fig. 6b) upon inclusion with $\beta$-CD. Otherwise, TCPP shifted to $464 \mathrm{~nm}$ (Fig. 6c) upon being complexed with $\mathrm{Pb}$ (II) after 30 min under $25^{\circ} \mathrm{C}$. The $\lambda_{\max }$ of the complex was slightly shifted (to $465 \mathrm{~nm}$ ) in the presence of $\beta$-CD (Fig. 6d).

The reaction of TCPP and $\mathrm{Pb}$ (II) ions in the absence of $\beta$-CD required $30 \mathrm{~min}$ at $25^{\circ} \mathrm{C}$. This complexation time was reduced to $4 \mathrm{~min}$ in the presence of $\beta$-CD, as shown in the inside window of Fig. 6. Although the magnitude of the acceleration effect of TPPS $_{4}$ was slightly better than TCPP, a comparison of the acceleration effect between TCPP and TPPS $_{4}$ was not appropriate directly, due to different $\mathrm{p} K_{\mathrm{a}}$ values of the porphyrin compound and the optimum condition of the reaction. Thus, it appears that the addition $\beta$-CD may be utilized to enhance the complexation rate between the anionic porphyrins and the metal cations, in general.

\section{Acceleration mechanism}

The results obtained under this experimental condition show that the complexation between water-miscible, anionic porphyrins, and metal ions is accelerated in the presence of $\beta$ - $\mathrm{CD}$, and proceeds due to the formation of a ternary complex

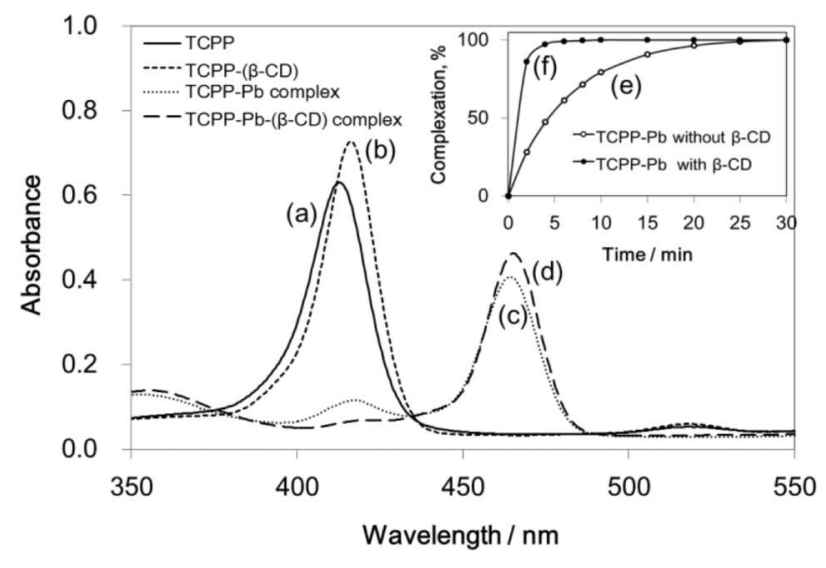

Fig. 6 Absorption spectra of (a) TCPP, (b) TCPP with $\beta$-CD, (c) PbTCPP complex, and (d) Pb-TCPP complex with $\beta$-CD. Spectrum a: $[\mathrm{TCPP}]_{\mathrm{T}}, 2.0 \mu \mathrm{M} ; \mathrm{pH}, 10.5$; and temperature, $25^{\circ} \mathrm{C}$. Spectrum b: $[\mathrm{TCPP}]_{\mathrm{T}}, 2.0 \mu \mathrm{M} ;[\beta-\mathrm{CD}]_{\mathrm{T}}, 1 \mathrm{mM} ; \mathrm{pH}, 10.5$; temperature, $25^{\circ} \mathrm{C}$; and reaction time, 4 min. Spectrum c: $[\mathrm{TCPP}]_{\mathrm{T}}, 2.0 \mu \mathrm{M} ;\left[\mathrm{Pb}^{2+}\right]_{\mathrm{T}}, 10 \mu \mathrm{M}$; $\mathrm{pH}, 10.5$; temperature, $25^{\circ} \mathrm{C}$; and reaction time, $30 \mathrm{~min}$. Spectrum d: $[\mathrm{TCPP}]_{\mathrm{T}}, 2.0 \mu \mathrm{M} ; \quad\left[\mathrm{Pb}^{2+}\right]_{\mathrm{T}}, \quad 10 \mu \mathrm{M} ; \quad[\beta-\mathrm{CD}]_{\mathrm{T}}, 1 \mathrm{mM} ; \mathrm{pH}, 10.5$; temperature, $25^{\circ} \mathrm{C}$; and reaction time, $4 \mathrm{~min}$. Inside window exhibits $\mathrm{TCPP}-\mathrm{Pb}(\mathrm{II})$ complexation percent versus reaction time. $[\mathrm{TCPP}]_{\mathrm{T}}$, $2.0 \mu \mathrm{M}$; $\left[\mathrm{Pb}^{2+}\right]_{\mathrm{T}}, 10 \mu \mathrm{M} ; \mathrm{pH}, 10.5 ;[\beta-\mathrm{CD}]_{\mathrm{T}}$, (e) 0 and (f) $1 \mathrm{mM}$; temperature, $25^{\circ} \mathrm{C}$; and detection wavelength, $\lambda_{\max }$, (e) $464 \mathrm{~nm}$ and (f) $465 \mathrm{~nm}$.

(cf. bicapped complex; $(\beta-\mathrm{CD})_{2}$-porphyrin-metal ion). This reaction proceeds according to the following sequence of reactions:

$$
\begin{aligned}
& \mathrm{TPPS}_{4}+2 \beta-\mathrm{CD} \quad \rightleftarrows \mathrm{TPPS}_{4}-(\beta-\mathrm{CD})_{2}
\end{aligned}
$$

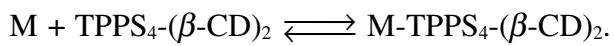

The rate constant for the binding interaction between $\mathrm{TPPS}_{4}$ and $\beta$-CD was too rapid to be measured, because the inclusion of TPPS $_{4}$ by $\beta$-CD was faster than that of metal complexation $\left(<1 \mathrm{~ms}\right.$ ) (cf. rate constants between TPPS $_{4}$ and $\beta$-CD in ethylene glycol- $\mathrm{H}_{2} \mathrm{O}$ (3:1) was previously reported). ${ }^{56,57}$ The free-base TPPS $_{4}$ was immediately incorporated by $\beta$-CD in aqueous solution to form the inclusion complex, $\mathrm{TPPS}_{4}-(\beta-\mathrm{CD})_{2}$.

The solubility of $\beta$-CD in water is lower than that of other CD (cf. solubility in water at $25^{\circ} \mathrm{C}: 145,18.5$, and $232 \mathrm{~g} / \mathrm{L}$ for $\alpha$-, $\beta$-, and $\gamma-\mathrm{CD}$, respectively), ${ }^{59}$ due to the relatively strong intermolecular hydrogen bonding. ${ }^{59}$ As such, the degree of freedom of TPPS $_{4}$ in aqueous solution is reduced upon its inclusion with the $\mathrm{CD}$. Furthermore, upon the addition of $\beta-\mathrm{CD}$, the dissociation reaction of the complex was relatively limited compared to the complexation promotion (based on the results of kinetic analysis). In addition, the $\mathrm{p} K_{\mathrm{a}}$ of $\mathrm{TPPS}_{4}$ became lower, and the original geometric torsion ${ }^{60}$ was slightly twisted upon $\mathrm{CD}$ inclusion. ${ }^{61,62}$ Consequently, the acceleration of metalporphyrin complexation with CD capping was caused by several factors: (1) an improvement of the complex stability upon the formation of the ternary bicapped complex $\left((\beta-C D)_{2}\right.$-porphyrinmetal ion), (2) suppression of the dissociation reaction of $\mathrm{TPPS}_{4}-\mathrm{Pb}$ by capping with $\beta$-CD, whose flexibility is limited due to low solubility in water, and (3) an improvement of reactivity between $\mathrm{TPPS}_{4}$ and $\mathrm{Pb}$ (II) ion due to a distortion of the porphyrin ring upon ionization and complexation with the $\beta$-CD. 


\section{Detection ability}

Under the optimized conditions $\left(\left[\mathrm{TPPS}_{4}\right]_{\mathrm{T}}=1.7 \mu \mathrm{M}\right.$ and $[\beta$ $C D]_{\mathrm{T}}=1 \mathrm{mM}$; wavelength $=466 \mathrm{~nm}$ ), quantitative linearity was obtained for the determination of $\mathrm{Pb}$ (II) using $\mathrm{TPPS}_{4}$ in the presence of $\beta$-CD. Quantitative results were obtained up to $2.5 \mu \mathrm{M} \mathrm{Pb}{ }^{2+}$ with a detection limit (signal-to-noise $=3$ ) of $9.0 \mathrm{nM}$. The correlation coefficient for the calibration curve was 0.985 , and the relative standard deviation contained an error of $2.0 \%(\mathrm{~Pb}: 1.0 \mu \mathrm{M}, n=5)$. There was no difference between the detection limit for $\mathrm{Pb}(\mathrm{II})$ in either the presence or absence of the $\beta-C D$; however, the reaction time was greatly diminished, as previously noted. Thus, the same sensitivity is achieved, but in a much more rapid time frame.

\section{Conclusions}

The rate of the complexation reaction between anionic porphyrins and 11 metal ions was found to be accelerated in the presence of $\beta$-cyclodextrin $(\beta$-CD) in aqueous media at room temperature without the need for additional heating or sonication. The addition of $\beta$-CD strongly impacted on the apparent acceleration of the complexation between porphyrin and metal ions. Using $\mathrm{Pb}(\mathrm{II})$ as the model ion, the complexation rate constant was enhanced by a factor of 2.4 , while the dissociation rate constant was diminished by a factor of 135 in the presence of added $\beta$-CD relative to that in its absence when the model anionic porphyrin, $\mathrm{TPPS}_{4}$, was employed. The formation equilibrium constant of the complex was 324-fold greater in the $\beta$-CD medium. The acceleration effect was confirmed not only for TPPS but also for anionic porphyrin, TCPP. The formation of a bicapped complex was demonstrated through the use of NMR spectroscopy and MS spectrometry. This acceleration effect is expected to be applicable to systems in which porphyrin ligands are employed for the determination of metal ions in chemical analysis, separation science and sensor techniques using not only UV-Vis spectrometry, but luminescence, electrochemical measurements and chromatographic application etc.

\section{Acknowledgements}

The authors gratefully acknowledge funding by JSPS Grant-inAid for Challenging Exploratory Research \#15K14198 and JSPS Grant-in-Aid for Scientific Research (B) \#15H03842.

\section{Supporting Information}

Supporting Information is available free of charge on the Web at http://www.jsac.or.jp/analsci/.

\section{References}

1. N. A. Rakow and K. S. Suslick, Nature, 2000, 406, 710.

2. K. Ueno, T. Imamura, and K. L. Cheng, "CRC Handbook of Organic Analytical Reagents", 2nd ed., 1992, CRC Press, Tokyo.

3. S. Igarashi, Bunseki Kagaku, 1997, 46, 1.

4. K. Kawamura, S. Igarashi, and T. Yotsuyanagi, Microchim. Acta, 2011, 172, 319.

5. Z. S. Yoon, A. Osuka, and D. Kim, Nat. Chem., 2009, 1, 113.
6. A. Yone, R. R. Carballo, D. A. Grela, I. N. Rezzano, and N. M. Vizioli, Electrophoresis, 2011, 32, 2840.

7. A. S. T. Kangwanwong, W. Pluempanupat, W. Parasuk, and H. E. Keenan, Sci. Asia, 2012, 38, 278.

8. X. Shu, Y. Wang, S. Zhang, L. Huang, S. Wang, and D. Hua, Talanta, 2015, 131, 198.

9. A. Yetisen, "Holographic Sensors", 2015, Springer International Publishing, 85.

10. N. Venkatramaiah, P. Carla, R. F. Mendes, F. A. A. Paz, and P. C. T. João, Anal. Chem., 2015, 87, 4515.

11. W. Qin, P. Parzuchowski, W. Zhang, and M. E. Meyerhoff, Anal. Chem., 2003, 75, 332.

12. Y. Zang, J. Lei, P. Ling, and H. Ju, Anal. Chem., 2015, 87, 5430 .

13. Y. He, J. Zhang, and J. Zhao, J. Phys. Chem. C, 2014, 118, 18325.

14. A. Manaka, M. Sakai, and S. Igarashi, Anal. Chim. Acta, $478,37$.

15. J. Xu, J. Wu, C. Zong, H. Ju, and F. Yan, Anal. Chem., 2013, 85, 3374.

16. P. Ling, J. Lei, L. Zhang, and H. Ju, Anal. Chem., 2015, 87, 3957.

17. M. Tabata and K. Ozutsumi, Bull. Chem. Soc. Jpn., 1992, 65, 1438.

18. J. Itoh, T. Yotsuyanagi, and K. Aomura, Anal. Chim. Acta, 1975, 74, 53.

19. K. Kalyanasundaram and M. Neumann-Spallart, J. Phys. Chem., 1982, 413, 5163.

20. M. Tabata and M. Tanaka, J. Chem. Soc. Dalton. Trans., 1983, 1955.

21. J. Itoh, M. Yamahira, T. Yotsuyanagi, and K. Aomura, Bunseki Kagaku, 1976, 25, 781.

22. S. Igarashi, H. Furukawa, and T. Kawakami, Anal. Proc. Incl. Anal. Commun., 1995, 32, 107.

23. M. Tabata, S. Koda, K. Yasuda, and H. Nomura, Bunseki Kagaku, 1995, 44, 221.

24. M. Tabata and M. Babasaki, Inorg. Chem., 1992, 31, 5268.

25. S. Funahashi, Y. Inada, and M. Inamo, Anal. Sci., 2001, 17, 917.

26. M. Tabata, TrAC-Trends Anal. Chem., 1991, 10, 128.

27. O. Horváth, R. Huszánk, Z. Valicsek, and G. Lendvay, Coord. Chem. Rev., 2006, 250, 1792.

28. Z. Valicsek, G. Lendvay, and O. Horváth, J. Phys. Chem. B, 2008, 112, 14509.

29. Z. Valicsek, O. Horváth, G. Lendvay, I. Kikaš, and I. Škorić, J. Photochem. Photobiol., A, 2011, 218, 143.

30. T. Yabutani, H. Kurokawa, Y. Hayashi, H. Higuchi, Y. Iwata, Y. Hashizume, S. Wada, Y. Hayashi, and J. Motonaka, Anal. Sci., 2010, 26, 407.

31. Y. Yin, T. Takayanagi, M. Oshima, K. Oshita, S. Motomizu, and Y. Murata, J. Flow Inject. Anal., 2013, 30, 45.

32. R. Czolk, J. Reichert, and H. J. Ache, Sens. Actuators, B, 1992, 7, 540.

33. T. Balaji, S. A. El-Safty, H. Matsunaga, T. Hanaoka, and F. Mizukami, Angew. Chem. Int. Ed., 2006, 45, 7202.

34. S. A. El-Safty, A. A. Ismail, H. Matsunaga, T. Hanaoka, and F. Mizukami, Adv. Funct. Mater., 2008, 18, 1485.

35. Z. Wang, C. J. Medforth, and J. A. Shelnutt, J. Am. Chem. Soc., 2004, 126, 15954.

36. M. Plaschke, R. Czolk, and H. J. Ache, Anal. Chim. Acta, 1995, 304, 107.

37. T. Saitoh, H. Hoshino, and T. Yotsuyanagi, Anal. Sci., 1991, 7, 495.

38. A. Shamim and P. Hambright, J. Inorg. Nucl. Chem., 1980, 42,1645 . 
39. K. Kawamura, S. Igarashi, and T. Yotsuyanagi, Inorg. Chim. Acta, 2007, 360, 3287.

40. S. Funahashi, Y. Ito, H. Kakito, M. I. Inamo, and Y. Hamada, Mikrochim. Acta, 1986, 88, 33.

41. D. K. Lavallee, "The Chemistry and Biochemistry of $\mathrm{N}$-substituted Porphyrins", 1987, VCH Publishers, New York.

42. K. Kawamura, S. Igarashi, and T. Yotsuyanagi, Anal. Sci., 1988, 4, 175

43. M. Tabata and M. Tanaka, Inorg. Chem., 1988, 27, 203.

44. K. Kawamura, S. Igarashi, and T. Yotsuyanagi, Microchim. Acta, 2006, 153, 145.

45. D. A. Buckingham, C. R. Clark, and W. S. Webley, J. Chem. Soc. Chem. Commun., 1981, 192.

46. H. Ishii and H. Koh, Bunseki Kagaku, 1979, 28, 473.

47. T. Makino and J.-I. Itoh, Clin. Chim. Acta, 1981, 111, 1.

48. K. Kawamura, K. Ikoma, S. Igarashi, H. Hisamoto, and T. Yao, Talanta, 2011, 84, 1318.

49. M. Tabata, Analyst, 1987, 112, 141.

50. M. Tabata and M. Tanaka, J. Chem. Soc. Chem. Commun., 1985, 3, 42.

51. S. Hamai and T. Koshiyama, J. Photochem. Photobiol., A,
1999, 127, 135.

52. K. Kano, R. Nishiyabu, and R. Doi, J. Org. Chem., 2005, $70,3667$.

53. J. Mosinger, M. Deumié, K. Lang, P. Kubát, and D. Wagnerová, J. Photochem. Photobiol., A, 2000, 130, 13.

54. J. H. Fuhrhop, Langmuir, 2014, 30, 1.

55. T. Niu and A. Li, J. Phys. Chem. Lett., 2013, 4, 4095.

56. K. Kano, N. Tanaka, H. Minamizono, and Y. Kawakita, Chem. Lett., 1996, 925.

57. K. Kano, R. Nishiyabu, T. Asada, and Y. Kuroda, J. Am. Chem. Soc., 2002, 124, 9937.

58. K. Kilian and K. Pyrzyńska, Talanta, 2003, 60, 669

59. T. Loftsson, P. Jarho, M. Másson, and T. Järvinen, Expert Opin. Drug Deliv., 2005, 2, 335.

60. P. Štěpánek, V. Andrushchenko, K. Ruud, and P. Bouř, $J$. Phys. Chem. A, 2012, 116, 778.

61. G. R. S. Andrade, T. D. S. Rezende, L. S. Barreto, L. E. Almeida, N. B. da Costa, and I. D. F. Gimenez, J. Phys. Conf. Ser., 2010, 249, 012037.

62. Y. Tsuchiya, A. Yamano, T. Shiraki, K. Sada, and S. Shinkai, Chem. Lett., 2011, 40, 99. 